\title{
Index of Contributors
}

Blau, K., Ph. D.

Queen Charlotte's Hospital for Women

Prenatal Biochemistry Unit

Department of Chemical Pathology

Queen Charlotte's Maternity Hospital

Goldhawk Road

London W6 OXG

Great Britain

Chalmers, R. A., Ph. D.

Section of Perinatal and Child Health

MRC Clinical Research Centre

Watford Road

Harrow Middlesex HA1 3UJ

Great Britain

Desiderio, D. M., Ph. D.

Stout Neuroscience

Mass Spectrometry Laboratory

University of Tennessee

800 Madison Avenue

Memphis, Tennessee 38163

U.S.A.

Ford, G. C., M.Sc.

Nutrition Research Group

Division of Clinical Sciences

MRC Clinical Research Centre

Watford Road

Harrow Middlesex HA1 3UJ

Great Britain

Gaskell, S. J., Ph. D.

Center for Experimental Therapeutics

Baylor College of Medicine

One Baylor Plaza

Houston, Texas 77030

U.S.A.
Halliday, D., Ph. D.

Nutrition Research Group

Division of Clinical Sciences

MRC Clinical Research Centre

Watford Road

Harrow Middlesex HA1 3UJ

Great Britain

Jackson, A. H., Ph. D.

Department of Chemistry

University College

P.O. Box 78

Cardiff CF1 1XL

Great Britain

Kamerling, J. P., Ph. D.

Department of Bio-Organic Chemistry

Transitorium III

Utrecht University

P.O. Box 80.075

NL-3508 TB Utrecht

The Netherlands

Kelly, R. W., Ph. D.

MRC Reproductive Biology Unit

Centre for Reproductive Biology

37 Chalmers Street

Edinburgh EH3 9EW

Great Britain

Kuksis, A., Ph. D.

Charles H. Best Institute

Banting and Best Department

of Medical Research

University of Toronto

112 College Street

Toronto, Ontario M5G 1L6

Canada 
Lawson, A. M., Ph. D.

Section of Clinical Mass Spectrometry

MRC Clinical Research Centre

Watford Road

Harrow Middlesex HA1 3UJ

Great Britain

Myher, J. J., Ph. D.

Charles H. Best Institute

Banting and Best Department

of Medical Research

University of Toronto

112 College Street

Toronto, Ontario M5G 1L6

Canada

Ramsden, D., Ph. D.

Dept. of Medicine

University of Birmingham

Queen Elizabeth Hospital

Edgbaston

Birmingham B15 2TH

Great Britain

Schram, K. H., Ph. D.

College of Pharmacy

Department of Pharmaceutical Sciences

University of Arizona

Tucson, Arizona 85721

U.S.A.
Setchell, K. D. R., Ph. D.

Department of Pediatrics

Children's Hospital Medical Center

University of Cincinnati

Elland \& Bethesda Avenues

Cincinnati, Ohio 045229

U.S.A.

Siekmann, L., Ph. D.

Institut für Klinische Biochemie

der Universität Bonn

Sigmund-Freud-Straße 25

D-5300 Bonn 1

Fed. Republic of Germany

Vliegenthart, J. F. G., Ph. D.

Department of Bio-Organic Chemistry

Transitorium III

Utrecht University

P.O. Box 80.075

NL-3508 TB Utrecht

The Netherlands 